\title{
Comparison of RAPD and ISSR markers for assessment of genetic diversity among endangered rare Dalbergia oliveri (Fabaceae) genotypes in Vietnam
}

\author{
D.T. Phong, V.T.T. Hien, T.T.V. Thanh and D.V. Tang \\ Department of Experimental Taxonomy and Genetic Diversity, \\ Vietnam National Museum of Nature, \\ Vietnam Academy for Science and Technology, Hanoi, Vietnam \\ Corresponding author: D.T. Phong \\ E-mail: dinhthiphong@hotmail.com
}

Genet. Mol. Res. 10 (4): 2382-2393 (2011)

Received January 14, 2011

Accepted July 18, 2011

Published October 6, 2011

DOI http://dx.doi.org/10.4238/2011.October.6.3

\begin{abstract}
Dalbergia oliveri is a leguminous tree of the Fabaceae family. This species is popular and valuable in Vietnam and is currently listed on the Vietnam Red List and on the IUCN Red List as endangered. Two PCR techniques using RAPD and inter-simple sequence repeat (ISSR) markers were used to make a comparative analysis of genetic diversity in this species. Fifty-six polymorphic primers (29 RAPD and 27 ISSR) were used. The RAPD primers produced 63 bands across 35 genotypes, of which 24 were polymorphic. The number of amplified bands varied from one to four, with a size range from 250 to $1400 \mathrm{bp}$. The percentage polymorphism ranged from 0 to 75. Amplification of genomic DNA of the 35 genotypes, using ISSR analysis, yielded 104 fragments, of which 63 were polymorphic. The number of amplified fragments using ISSR primers ranged from one to nine and varied in size from 250 to $1500 \mathrm{bp}$. The percentage polymorphism ranged from 0 to 100 . ISSR markers were relatively more efficient than RAPDs. The
\end{abstract}


mental test between two Jaccard's similarity matrices gave $r \geq 0.802$, showing good fit correlation between ISSRs and RAPDs. Clustering of isolates remained more or less the same for RAPDs compared to combined RAPD and ISSR data. The similarity coefficient ranged from 0.785 to $1.000,0.698$ to 0.956 and 0.752 to 0.964 with RAPD, ISSR, and the combined RAPD-ISSR dendrogram, respectively.

Key words: Molecular marker; ISSR; RAPD

\section{INTRODUCTION}

Dalbergia oliveri is a leguminous tree species in the Fabaceae family, widely distributed in Myanmar, Thailand, Laos, Cambodia, and southern Vietnam. It grows from 15 to $30 \mathrm{~m}$ in height. The wood of this tree has yellowish-white sapwood and dark brown heartwood and is valuable for ornamental work, including wood decorations and furniture. In the market, the lumber is sold under the names Burmese Rosewood, Laos Rosewood, Asian Rosewood, and "Cam lai" or "Trac lai" (in Vietnamese). In Vietnam, the huge demand for D. oliveri has placed this species in danger of extinction at level EN Ala,c,d (Dang and Nguyen, 2007); it is forbidden to exploit, ship or store wood from this tree, according to Decision 32/2006/ND-CP issued by the Vietnam government. Natural populations of D. oliveri are disappearing and only limited numbers of individuals are found in the remaining forest fragments of the southern part of Vietnam (Oldfield et al., 1998). Thus, in order to effectively plan gene conservation strategies, it is essential to have an understanding of the patterns of genetic variation in this population to protect it from further genetic corrosion.

Recent advances in molecular biology, principally the development of PCR, have provided powerful techniques for characterizing and evaluating genetic diversity and population evolution. RAPD (Williams et al., 1990) and ISSR markers (Zietkiewicz et al., 1994) are two widely applicable techniques to identify relationships at the species and cultivar levels (Raina et al., 2001; Martins et al., 2003; Gupta et al., 2008; Arif et al., 2009), because they are rapid, simple to perform and inexpensive; they do not require prior knowledge of DNA sequences and only a small amount of DNA is needed (Esselman et al., 1999). Genetic diversity of some Dalbergia species has been evaluated with molecular techniques; however, genetic studies of rare and valuable Dalbergia species of Vietnam, which are in danger of extinction due to overexploitation, have not been reported.

We investigated genetic variation among 35 genotypes of $D$. oliveri using RAPD and ISSR markers and compared the efficiency of these markers. This information will aid in the long-term objective of efficient identification, conservation, exploitation, and recreational use of this species.

\section{MATERIAL AND METHODS}

Samples collected from the Yok Don National Park, the largest of Vietnam's nature preserves and one of seven internationally important Centers of Plant Diversity in Vietnam. This park encompasses over $1000 \mathrm{~km}^{2}$ and extends from eastern Cambodia into northern Dak Lak and southern Gia Lai Provinces in Vietnam (Figure 1). The topography of most of this park is flat, with an elevation of approximately $200 \mathrm{~m}$. 


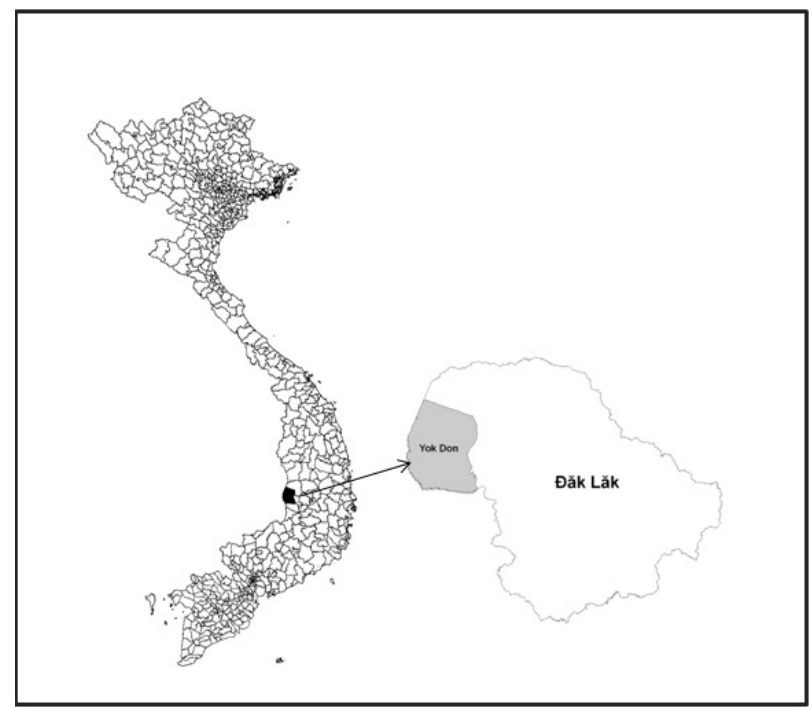

Figure 1. Location of the Dalbergia oliveri population in the Yok Don National Park.

Thirty-five D. oliveri genotypes were used for this study (named Do1-35). Total genomic DNA was isolated from leaves and wood using the method described by Porebski et al. (1997). The concentration of DNA was determined with a UV-visible light spectrophotometer (UVS 2700, Labomed, USA), and the DNA samples were diluted to $20 \mathrm{ng} / \mu \mathrm{L}$ and used as templates for PCR amplification.

\section{RAPD marker amplification}

Arbitrary decamer primers used in this study were obtained from Alpha DNA, Canada (Table 1). PCR amplifications were performed in $25 \mu \mathrm{L}$ volumes, using a GeneAmp PCR System 9700 (AppliedBiosystems USA). The reaction mixtures contained $10 \mathrm{mM}$ Tris- $\mathrm{HCl}$, $\mathrm{pH} 8.3,50 \mathrm{mM} \mathrm{KCl}, 10-20$ ng genomic DNA, 10 pmol primer, $2-4 \mathrm{mM} \mathrm{MgCl}_{2}, 300-400 \mu \mathrm{M}$ of each dNTP, and 0.8-1.2 U Taq DNA polymerase (Amersham). The temperature profile consisted of an initial denaturation step at $94^{\circ} \mathrm{C}$ for $4 \mathrm{~min}$, followed by 45 cycles: $92^{\circ} \mathrm{C}$ for 1 $\min , 35^{\circ} \mathrm{C}$ for $1 \mathrm{~min}$, and $72^{\circ} \mathrm{C}$ for $1 \mathrm{~min}$. After the final cycle, samples were incubated for 10 min to ensure complete extension and then stored at $4^{\circ} \mathrm{C}$. The PCR products were separated on $1.5 \%$ agarose gel in $0.5 \mathrm{X}$ TBE buffer (Tris-borate-ethylenediaminetetraacetic acid). The size of amplified DNA fragments was estimated with 1-kb ladders (Fermentas, USA). The gels were visualized under UV using gel documentation (CSL-MiCRODOC, Cleaver, England).

\section{ISSR marker amplification}

ISSR primers for ISSR were obtained from Integrated DNA Technologies, USA (Table 1). The reaction mixtures contained $10 \mathrm{mM}$ Tris- $\mathrm{HCl}, \mathrm{pH} 8.3,50 \mathrm{mM} \mathrm{KCl}, 10-20$ ng genomic DNA, 10 pmol primer, $2-4 \mathrm{mM} \mathrm{MgCl}_{2}, 300-400 \mu \mathrm{M}$ of each dNTP, and 0.8-1.2 U Taq DNA polymerase (Amersham). The temperature profile consisted of an initial denaturation 


\begin{tabular}{|c|c|c|c|c|c|c|c|c|}
\hline$\#$ & Primer code & $\begin{array}{l}\text { Primer sequence } \\
\text { range }(\mathrm{bp})\end{array}$ & Amplified product & PIC & $\begin{array}{l}\text { Poly- } \\
\text { bands }\end{array}$ & $\begin{array}{l}\text { Mono- } \\
\text { bands }\end{array}$ & $\begin{array}{c}\text { Total } \\
\text { bands }\end{array}$ & $\begin{array}{l}\text { Average expected } \\
\text { gene diversity }(\mathrm{H} i)\end{array}$ \\
\hline \multicolumn{9}{|c|}{ RAPD primers } \\
\hline 1 & OPC19 & GTTGCCAGCC & 750 & 0 & 0 & 1 & 1 & 0.000 \\
\hline 2 & OPP08 & ACATCGCCCA & $600-1400$ & 0 & 0 & 2 & 2 & 0.000 \\
\hline 3 & OPP19 & GGGAAGGACA & $250-750$ & 0.360 & 3 & 1 & 4 & 0.281 \\
\hline 4 & $\mathrm{OPC} 05$ & GATGACCGCC & 750 & 0 & 0 & 1 & 1 & 0.000 \\
\hline 5 & OPR15 & GGACAACGAG & 600 & 0 & 0 & 1 & 1 & 0.000 \\
\hline 6 & OPN16 & AAGCGACCTG & $1200-1300$ & 0 & 0 & 2 & 2 & 0.000 \\
\hline 7 & OPG13 & CTCTCCGCCA & $300-750$ & 0.241 & 2 & 1 & 3 & 0.071 \\
\hline 8 & OPD13 & GGGGTGACGA & $600-1000$ & 0.037 & 1 & 1 & 2 & 0.122 \\
\hline 9 & OPE20 & AACGGTGACC & $600-1100$ & 0.346 & 2 & 1 & 3 & 0.174 \\
\hline 10 & OPD20 & ACCCGGTCAC & 800 & 0 & 0 & 1 & 1 & 0.000 \\
\hline 11 & OPH03 & AGACGTCCAC & $450-1400$ & 0.544 & 3 & 1 & 4 & 0.105 \\
\hline 12 & OPD03 & GTCGCCGTCA & $600-1400$ & 0 & 0 & 4 & 4 & 0.000 \\
\hline 13 & UBC348 & CACGGCTGCG & $450-650$ & 0.141 & 1 & 1 & 2 & 0.250 \\
\hline 14 & OPA15 & TTCCGAACCC & 4500 & 0 & 0 & 1 & 1 & 0.000 \\
\hline 15 & OPE14 & TGCGGCTGAG & $600-900$ & 0.415 & 1 & 1 & 2 & 0.028 \\
\hline 16 & OPW13 & TGCGCCCTTC & $400-800$ & 0.226 & 2 & 2 & 4 & 0.075 \\
\hline 17 & OPB05 & GTGAGGCGTC & 850 & 0 & 0 & 1 & 1 & 0.000 \\
\hline 18 & $\mathrm{OPC} 02$ & GGAAGTCGCC & $1100-1400$ & 0.020 & 1 & 2 & 3 & 0.067 \\
\hline 19 & OPH04 & GGAAGCCAAC & $500-900$ & 0.139 & 2 & 2 & 4 & 0.233 \\
\hline 20 & OPP15 & GGAAGCCAAC & $300-700$ & 0.287 & 2 & 1 & 3 & 0.287 \\
\hline 21 & RA142 & CCTTGACGCA & 600 & 0 & 0 & 1 & 1 & 0.000 \\
\hline 22 & OPB06 & ACGCCCAGGT & 600 & 0 & 0 & 1 & 1 & 0.000 \\
\hline 23 & OPV06 & CTGCTGGGAC & $600-950$ & 0.195 & 1 & 2 & 3 & 0.095 \\
\hline 24 & OPB10 & CCCGTTGCCT & $400-850$ & 0.423 & 3 & 1 & 4 & 0.186 \\
\hline 25 & OPR08 & CCCGTTGCCT & 450 & 0 & 0 & 1 & 1 & 0.000 \\
\hline 26 & UBC25 & TGTAGCTGGG & 300 & 0 & 0 & 1 & 1 & 0.000 \\
\hline 27 & OPN11 & GAAACACCCC & $400-1400$ & 0 & 0 & 2 & 2 & 0.000 \\
\hline 28 & OPQ05 & GTAGACCCGT & 350 & 0 & 0 & 1 & 1 & 0.000 \\
\hline 29 & OPO04 & CACAGCGACA & 650 & 0 & 0 & 1 & 1 & 0.000 \\
\hline Total & & & & 3.374 & 24 & 39 & 63 & 1.974 \\
\hline Mean & & & & 0.116 & 0.827 & 1 & 2.17 & 0.068 \\
\hline \multicolumn{9}{|c|}{ ISSR primers } \\
\hline 1 & ISSR1 & $(\mathrm{CAG})_{5}$ & $450-1100$ & 0 & 0 & 3 & 3 & 0.000 \\
\hline 2 & ISSR2 & $(\mathrm{CAA})_{5}$ & $350-800$ & 0.063 & 4 & 0 & 4 & 0.207 \\
\hline 3 & ISSR3 & $(\mathrm{GACA})_{4}$ & $400-700$ & 0.180 & 3 & 0 & 3 & 0.222 \\
\hline 4 & ISSR5 & $(\mathrm{CCG})_{6}$ & $500-1500$ & 0.092 & 1 & 3 & 4 & 0.120 \\
\hline 5 & ISSR6 & $(\mathrm{CTC})_{6}$ & $800-1200$ & 0 & 0 & 4 & 4 & 0.000 \\
\hline 6 & ISSR7 & $(\mathrm{GGC})_{6}$ & $400-1200$ & 0 & 0 & 5 & 5 & 0.000 \\
\hline 7 & ISSR8 & $(\mathrm{GAA})_{6}$ & $250-800$ & 0.205 & 2 & 3 & 5 & 0.121 \\
\hline 8 & ISSR10 & $(\mathrm{CTC})_{8}$ & $700-1200$ & 0.108 & 2 & 2 & 4 & 0.235 \\
\hline 9 & ISSR11 & $(\mathrm{CCA})_{5}$ & $400-800$ & 0.049 & 3 & 1 & 4 & 0.154 \\
\hline 10 & ISSR12 & $(\mathrm{CCCT})_{4}$ & 800 & 0 & 0 & 1 & 1 & 0.000 \\
\hline 11 & ISSR13 & $(\mathrm{GT})_{8} \mathrm{C}^{4}$ & 700 & 0 & 0 & 1 & 1 & 0.000 \\
\hline 12 & ISSR14 & $(\mathrm{CTCT})_{4} \mathrm{GTC}$ & $400-900$ & 0.151 & 4 & 0 & 4 & 0.398 \\
\hline 13 & ISSR15 & $(\mathrm{CA})_{8} \mathrm{~A}^{4}$ & $300-1200$ & 0.263 & 9 & 0 & 9 & 0.387 \\
\hline 14 & ISSR17 & $(\mathrm{CT})_{8}^{8} \mathrm{~T}$ & $400-800$ & 0.361 & 4 & 0 & 4 & 0.416 \\
\hline 15 & ISSR18 & $(\mathrm{CT})_{8}^{8} \mathrm{~A}$ & 500 & 0 & 0 & 1 & 1 & 0.000 \\
\hline 16 & ISSR46 & $(\mathrm{AG})_{8}^{\circ} \mathrm{T}$ & $300-750$ & 0.144 & 4 & 1 & 5 & 0.285 \\
\hline 17 & ISSR51 & $(\mathrm{GA})_{8}^{8} \mathrm{~A}$ & $300-950$ & 0.299 & 4 & 2 & 6 & 0.188 \\
\hline 18 & ISSR55 & $(\mathrm{AC})_{8}^{8} \mathrm{~T}$ & $550-900$ & 0.211 & 2 & 3 & 5 & 0.134 \\
\hline 19 & ISSR56 & $(A C)_{8} G$ & $450-1000$ & 0.289 & 2 & 1 & 3 & 0.143 \\
\hline 20 & ISSR59 & $(\mathrm{GA})_{8} \mathrm{CT}$ & $500-900$ & 0.115 & 1 & 2 & 3 & 0.163 \\
\hline 21 & ISSR61 & $(\mathrm{AC})_{8}^{8} \mathrm{TG}$ & $400-850$ & 0.423 & 3 & 1 & 4 & 0.186 \\
\hline 22 & ISSR62 & CTC $(\mathrm{AG})_{7}$ & $500-1200$ & 0 & 0 & 3 & 3 & 0.000 \\
\hline 23 & ISSR63 & CTC $(\mathrm{GA})_{7}$ & $300-900$ & 0.290 & 2 & 1 & 3 & 0.261 \\
\hline 24 & ISSR64 & $\mathrm{ACA}(\mathrm{GT})_{7}$ & $300-800$ & 0.163 & 5 & 0 & 5 & 0.368 \\
\hline 25 & ISSR65 & $\mathrm{CAC}(\mathrm{TG})_{7}$ & $400-800$ & 0.207 & 5 & 0 & 5 & 0.343 \\
\hline 26 & ISSR67 & $(\mathrm{ATG})_{6}$ & $500-800$ & 0.076 & 2 & 1 & 3 & 0.222 \\
\hline 27 & ISSR69 & $(\text { GGGTG })_{3}$ & $500-1000$ & 0.277 & 1 & 2 & 3 & 0.019 \\
\hline Total & & & & 3.966 & 63 & 41 & 104 & 4.572 \\
\hline Mean & & & & 0.147 & 2.33 & 1.52 & 3.85 & 0.169 \\
\hline
\end{tabular}

$\mathrm{PIC}=$ polymorphism information content; Poly-bands = polymorphic bands; Mono-bands = monomorphic bands 
step at $94^{\circ} \mathrm{C}$ for $4 \mathrm{~min}$, followed by 35 cycles: $94^{\circ} \mathrm{C}$ for $1 \mathrm{~min}, 38^{\circ}-55^{\circ} \mathrm{C}$ for $1 \mathrm{~min}$, and $72^{\circ} \mathrm{C}$ for $1 \mathrm{~min}$. After the final cycle, samples were incubated for $10 \mathrm{~min}$ to ensure complete extension. The product was stored at $4^{\circ} \mathrm{C}$. The PCR products were separated on $1.5 \%$ agarose gel in $0.5 \mathrm{X}$ TBE buffer. The size of amplified DNA fragments was estimated with 1-kb ladders (Fermentas). The gels were visualized under UV using gel documentation (CSL-MiCRODOC).

\section{Data analysis}

DNA fingerprints were scored for the presence (1) or absence (0) of bands of various molecular weight sizes in the form of a binary matrix. The Simqual program was used to calculate Jaccard's coefficients (Jaccard, 1908); these were calculated as follows: $\mathrm{S}_{\mathrm{ij}}=\mathrm{a} /(\mathrm{a}+\mathrm{b}+\mathrm{c})$, where $S i j$ is the coefficient of similarity between two individuals $i$ and $j ; a$ is the number of fragments shared by samples; $b$ represents amplified fragments in sample $i$, and $c$ represents fragments in sample $j$. Coefficient correlation ( $\mathrm{r}$ ) provided a measure of the relatedness between the two matrices. The GenAlEx software (Peakall and Smouse, 2001) was used to calculate a principal coordinates analysis (PCA) that plotted the relationship between distance matrix elements based on their first two principal coordinates. Regression between two matrices obtained with two marker types was estimated using Nei's genetic diversity index. This yielded the regression $(\mathrm{r} 2)$, which is a measure of relatedness between two matrices. In this case, the matrix regression corresponds to two independently derived dendrograms. The UPGMA-based dendrogram was constructed using the NTSYS 2.0 software, version 2.0 (Rohlf, 1992). The Win-Boot software (Yap and Nelson, 1996) was used to compute bootstrap-based $\mathrm{P}$ values to assess the strength of evidence for clustering; these data were bootstrapped with 1000 replications, a long Jaccard's coefficient. The polymorphism information content (PIC) of each locus was determined, as described by Weir (1990): PIC $=1-\sum \mathrm{P} i j^{2}$, where $P i$ is the frequency of the $i$ th allele in the genotypes. Average expected gene diversity was calculated using the formula: $\mathrm{Hi}=(\mathrm{h} 1+\mathrm{h} 2) /$ total number of loci, where $h 1$ and $h 2$ [i.e., $h j=\left(1-\mathrm{p}^{2}-\mathrm{q}^{2}\right)$ ] represent intralocus gene diversity.

\section{RESULTS}

\section{RAPD band pattern}

PCR amplification of DNA, using 29 primers for RAPD analysis, produced 63 DNA fragments that could be scored in all genotypes. The number of amplified fragment varied from one (OPC19, OPP08, OPC05, OPR15, OPN16, OPD20, OPD03, OPA15, OPB05, RA142, OPB06, OPR08, OPN11, UBC25, OPQ05, and OPO04) to four (OPP19, OPH03, OPD03, OPW13, OPH04, and OPB10), which varied in size from 250 to $1400 \mathrm{bp}$. Of the 63 amplified bands, 24 were polymorphic, with an average of 0.83 polymorphic bands per primer. Percent polymorphism ranged from 0 (OPC19, OPP08, OPC05, OPR15, OPN16, OPD20, OPD03, OPA15, OPB05, RA142, OPB06, OPR08, OPN11, UBC25, OPQ05, and OPO04) to 75 (OPP19 and OPB10), with an average percentage polymorphism of 25.57. The PIC value varied from 0 (OPC19, OPP08, OPC05, OPR15, OPN16, OPD20, OPD03, OPA15, OPB05, RA142, OPB06, OPR08, OPN11, $\mathrm{UBC} 25$, OPQ05, and $\mathrm{OPO} 04)$ to 0.544 (OPH03); the average expected gene diversity ranged from 0 (OPC19, OPP08, OPC05, OPR15, OPN16, OPD20, OPD03, OPA15, OPB05, RA142, OPB06, OPR08, OPN11, UBC25, OPQ05, and OPO04) to 0.287 (OPD15) across all genotypes. 
Figure 2 shows a representation of the extensive polymorphism observed among the $D$. olive$r i$ genotypes, as revealed by RAPD primer OPH04. A dendrogram based on UPGMA analysis grouped the 35 genotypes into five main clusters (Figure 3A) with Jaccard's similarity coefficient ranging from 0.785 (Do1 and Do22 and Do23) to 1.00 (Do22 and Do23; Do34 and Do35). Genotypes Do1 and Do2 were grouped into two clusters, distinct from each other. Clusters III, IV and V comprise 18 (Do3, Do4, Do5, Do6, Do7, Do8, Do9, Do10, Do11, Do12, Do14, Do15, Do16, Do17, Do18, Do19, Do21, and Do26), 11 (Do13, Do20, Do22, Do23, Do24, Do25, Do27, Do28, Do29, Do30, and Do31), and four (Do32, Do33, Do34, and Do35) genotypes, respectively. Among them, genotypes Do22 and Do23, Do34, and Do35 appeared to be closest to each other, with a 1.00 similarity coefficient, while Do1 and Do2 exhibited maximum similarity (similarity coefficient 0.785 ) with each other. The results of PCA were comparable to the cluster analysis (Figure 4A). The first three most informative principal components explained $70.6 \%$ of the total variation. Genotype Do1 appears to be distinct from other genotypes in the PCA.

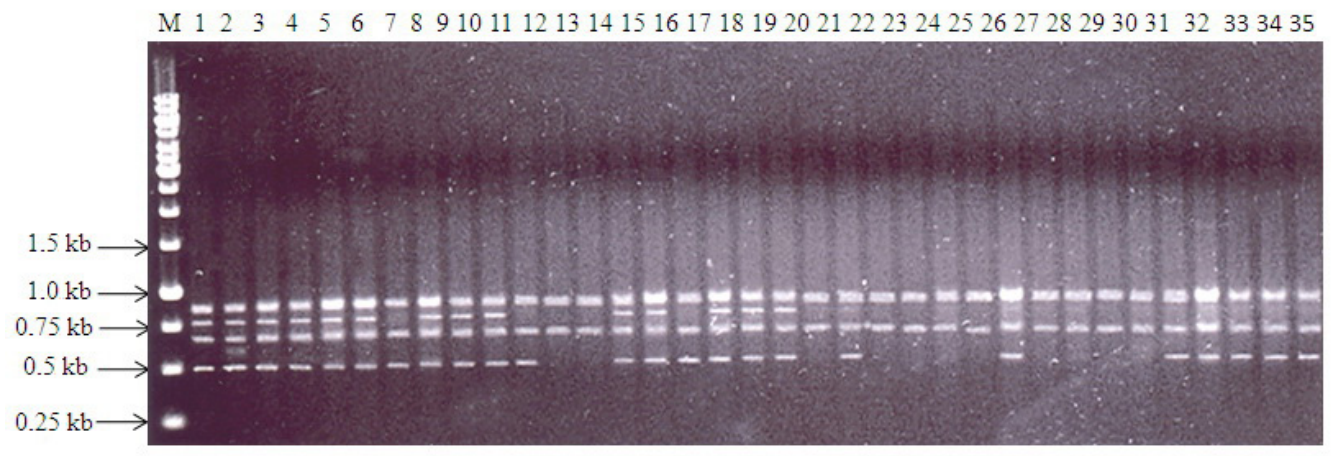

RAPD-OPH04

Figure 2. The RAPD profile of 35 Dalbergia oliveri genotypes produced with primer OPH04 (lane M is a 1-kb ladder and lanes 1 to 35 represent different $D$. oliveri genotypes).

\section{ISSR band pattern}

Twenty-seven ISSR oligonucleotides (Table 1) were used for amplification of all the 35 genotypes. Figure 5 shows the observed polymorphism among the $D$. oliveri genotypes using the ISSR15 primer. ISSR primers produced different numbers of DNA fragments, depending on their simple sequence repeat motifs (Figure 5). The 27 primers produced 104 bands across 35 genotypes, of which 63 were polymorphic, giving $52.5 \%$ polymorphism. The number of bands ranged from one (ISSR12, ISSR13 and ISSR18) to nine (ISSR15) and varied in size from 250 to $15,000 \mathrm{bp}$. Average number of bands and polymorphic bands per primer were 3.85 and 2.33 , respectively. Percentage polymorphism ranged from 0 (ISSR1, ISSR6, ISSR7, ISSR12, ISSR13, ISSR18, and ISSR62) to 100 (ISSR2, ISSR3, ISSR14, ISSR15, ISSR17, ISSR64, and ISSR65), with an average of 52.5\%, and PIC values varied from 0 (ISSR1, ISSR6, ISSR7, ISSR12, ISSR13, ISSR18, and ISSR62) to 0.423 (ISSR61), with an average of 0.147 , while average expected gene diversity ranged from 0 (ISSR1, ISSR6, ISSR7, ISSR12, ISSR13, ISSR18, and ISSR62) to 0.416 (ISSR17) across all the genotypes of $D$. oliveri. 
A

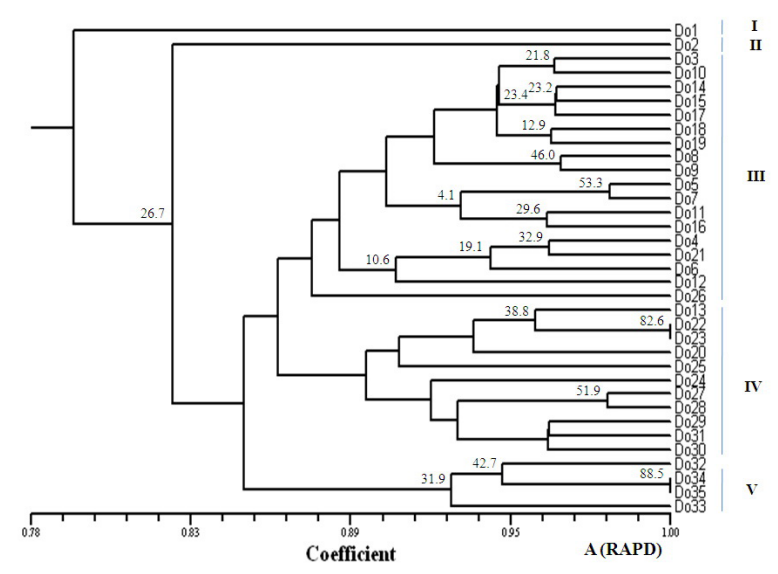

B

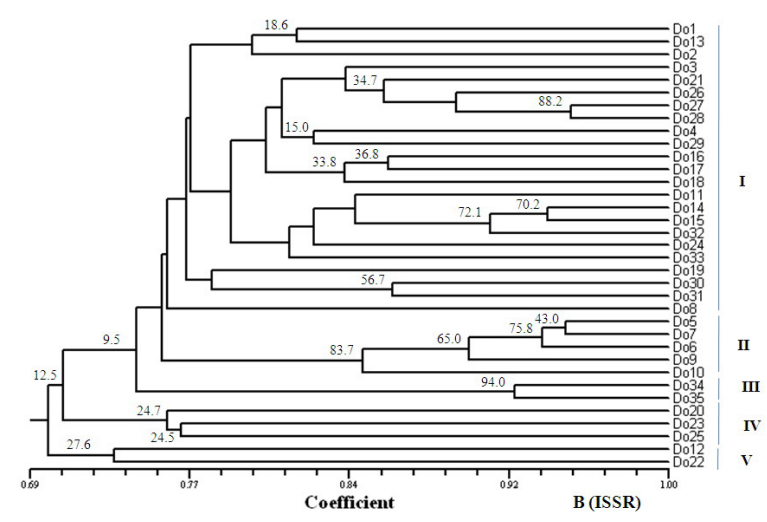

C

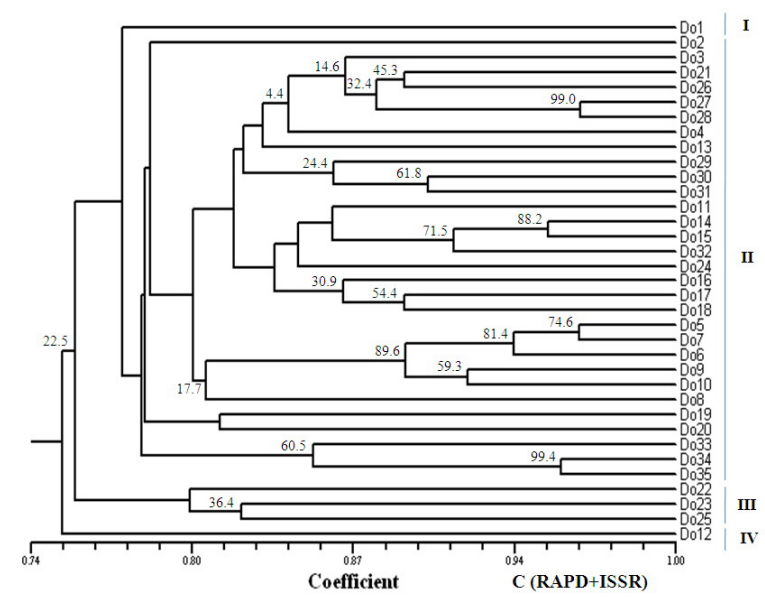

Figure 3. Dendrogram constructed using UPGMA based on Jaccard's coefficient. The numbers at the forks indicate the confidence limits for the grouping of those genotypes in a branch, based on 1000 cycles in bootstrap analysis using the Winboot program. The scale bar indicates the similarity index. A. RAPD data-based dendrogram. B. ISSR data-based dendrogram. C. Combined (ISSR and RAPD) data-based dendrogram. 

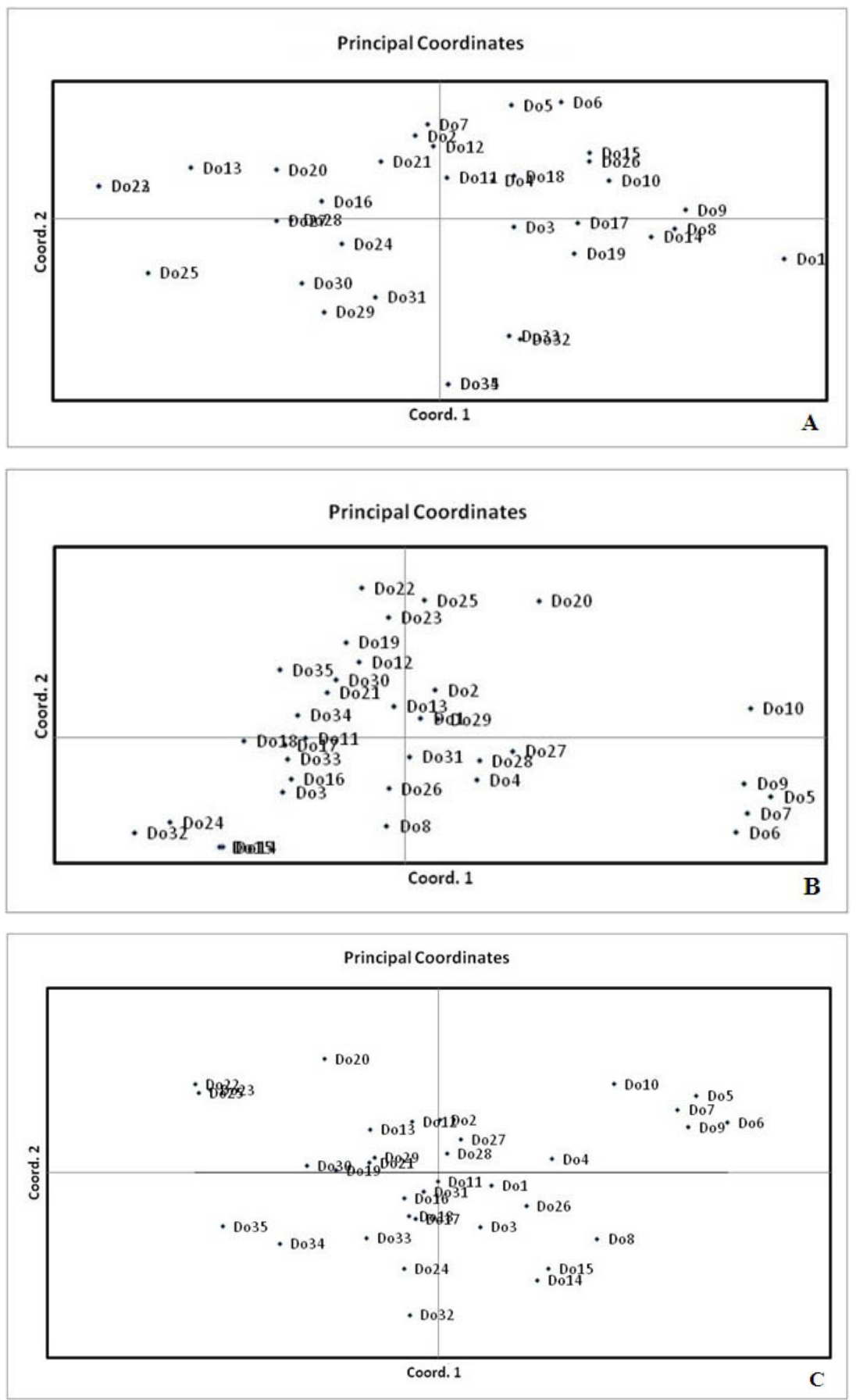

Figure 4. PCA across 35 Dalbergia oliveri genotypes. A. RAPD data-based MDS. B. ISSR data-based MDS. C. Combined (ISSR and RAPD) data-based PCA. 


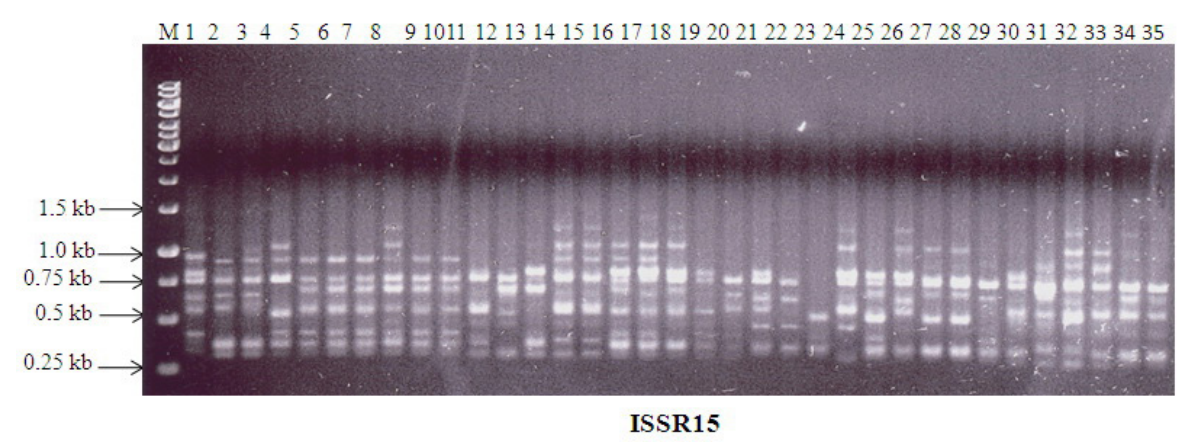

Figure 5. The ISSR profile of 35 Dalbergia oliveri genotypes produced with primer ISSR15 (lane M is 1-kb ladder and lanes 1 to 35 represent different $D$. oliveri genotypes).

A dendrogram based on UPGMA analysis with ISSR data is shown in Figure 3B. Jaccard's similarity coefficient ranged from 0.661 (Do8 and Do23) to 0.952 (Do27 and Do28). The 35 genotypes were grouped into five clusters. Cluster I comprises Do1, Do13, Do2, Do3, Do21, Do26, Do27, Do28, Do4, Do29, Do16, Do17, Do18, Do11, Do14, Do15, Do32, Do24, Do33, Do19, Do30, Do31, and Do8. Cluster II comprises Do5, Do7, Do6, Do9, and Do10. Cluster III comprises Do34 and Do35. Cluster IV comprises Do20, Do23 and Do25, and two germplasms (Do18 and Do21) form Cluster V. Among the clusters, cluster II had more subclusters (seven) than the other, while in this sub-cluster two genotype pairs Do27 and Do28, and Do5 and Do7, had maximum similarity (coefficient 0.964). The result of PCA was comparable to the cluster analysis (Figure 4B). The first three are the most informative principal components, explaining $62.3 \%$ of the total variation.

\section{Combined (ISSR and RAPD) data}

The ISSR and RAPD data were combined for UPGMA cluster analysis. The dendrogram and cluster analysis gave a similar clustering pattern to that of ISSR and RAPD analysis, separately, with Jaccard's similarity coefficient ranging from 0.742 to 0.964 . The three-dimensional ordination confirmed the cluster analysis results, showing that Do22, Do23 and Do25; Do5, Do6, Do7, Do9, and Do10, and Do14 and Do15 were separated from the other groups. Four dendrograms were produced based on both ISSR and RAPD data (Figure 3C), in which the clustering patterns are closer to ISSR analysis than RAPD analysis. The matrices were compared using Mantel (1967) test and revealed high correlation values between the two markers $(\mathrm{r}>0.802)$, which indicates a good fit among RAPD and ISSR marker systems. Thirty-five isolates were grouped in four clusters. The results of PCA analysis were comparable to the cluster analysis (Figure 4C). The three most informative PCA components explained $62.5 \%$ of the total variation.

\section{DISCUSSION}

The diversity of the samples was revealed by both RAPD and ISSR markers. Eightyseven polymorphic bands unambiguously discriminated $35 \mathrm{D}$. oliveri genotypes into four major clusters. Both ISSR and RAPD markers exhibited 38.6\% polymorphism. We found high genetic variability among different genotypes of $D$. oliveri in the Yok Don National Park. 
RAPD and ISSR molecular markers have been commonly used in population genetics studies and for detecting clonal diversity in many species (Parsons et al., 1997; Esselman et al., 1999; Li and Ge, 2001; Chen et al., 2006; Gupta et al., 2008; Arif et al., 2009). RAPDs have been used for evaluating genetic diversity within populations of Dalbergia sisso, D. latifolia, D. paniculata, D. assamica, and D. spinosa (Rout et al., 2003). Andrianoelina et al. (2006) also quantified and analyzed the genetic variation of $D$. monticola, using RAPDs.

Irrespective of the type of marker used, two pairs of germplasms, Do5-Do7 and Do27Do28, formed distinct clusters. The ISSR and RAPD makers showed that the similarity coefficient of two genotype pairs Do22-Do23 and Do34-Do35 was 1.000 (complete similarity). Although both RAPD and ISSR markers separated 35 germplasms into five main groups, clustering of genotypes within groups was not similar. A possible explanation for this difference is that the two techniques targeted different portions of the genome. These differences may also be attributed to sampling errors and/or the level of polymorphism detected, reinforcing the importance of the number of loci and their coverage of the overall genome for obtaining reliable estimates of genetic relationships among cultivars (Gopalakrishna, 2004; Gupta et al., 2008; Souframanien and Arif et al., 2009).

The correlation between Jaccard's similarity values obtained from RAPD and ISSR marker techniques was $r>0.8$. This indicates the good fit correlation between ISSR- and RAPD-based similarities. The ISSR method has been reported to be more reproducible (Nagaoka and Ogihara, 1997; Prevost and Wilkinson, 1999; Goulão and Oliveira, 2001) and produces more complex marker patterns than the RAPD approach (Parsons et al., 1997; Moreno et al., 1998; Chowdhury et al., 2002). ISSRs are advantageous for differentiating closely related cultivars and have been used for cultivar identification in numerous plant species, including rice (Blair et al., 1999; Joshi et al., 2000), grapes (Moreno et al., 1998), wheat (Nagaoka and Ogihara, 1997), apples (Goulão and Oliveira, 2001), mulberries (Zhao et al., 2006), and strawberries (Arnau et al., 2003).

However, based on PIC values (RAPD $=0.544$; ISSR $=0.423$ ), average expected gene diversity $(\mathrm{RAPD}=0.068$; ISSR $=0.169)$, percent polymorphism $(\mathrm{RAPD}=25.57$; ISSR $=52.53)$, and similarity matrix, the ISSR markers were marginally more informative than RAPD markers in the assessment of genetic diversity in D. oliveri (Table 2). This finding is opposite to that reported by Arif et al. (2009), who worked with Shisham (D. sisso). Some researchers have shown that ISSR markers are distributed throughout the genome and may be associated with functionally important loci (Penner, 1996; Esselman et al., 1999), while RAPD markers are located in non-coding regions and therefore are selectively neutral (Bachmann, 1997; Landergott et al., 2001). However, we cannot yet conclude that ISSR markers are functionally more important than RAPDs.

\begin{tabular}{lccc} 
Table 2. Genetic variation of 35 genotypes of Dalbergia oliveri compared using RAPDs and ISSRs. & RSSR & RAPD + ISSR \\
\hline Primers & RAPD & 56 \\
\hline Numbers of primers used & 29 & 27 & $250-1500$ \\
Amplified product range (bp) & $250-1400$ & 63 & 87 \\
Total number of polymorphic bands & 24 & 2.33 & 1.554 \\
Average numbers of polymorphic bands & 0.827 & 41 & 80 \\
Total number of monomorphic bands & 39 & 1.52 & 1.42 \\
Average number of monomorphic bands & 1 & 104 & 167 \\
Total number of bands & 63 & 3.85 & 2.982 \\
Average number of bands & 2.17 & 52.53 & 38.57 \\
\% Polymorphic bands & 25.57 & 0.147 & 0.131 \\
Mean PIC & 0.116 & 0.169 & 0.117 \\
Mean expected gene diversity (Hi) & 0.068 & & \\
\hline
\end{tabular}

$\mathrm{PIC}=$ polymorphism information content. 


\section{ACKNOWLEDGMENTS}

Research supported by the National Foundation for Science and Technology Development (NAFOSTED) of Vietnam. The authors gratefully acknowledge the assistance of Mr. Binh Nguyen Quoc (Department of Botany, Vietnam National Museum of Nature) and the Vietnam's Yor Don National Park for providing research materials.

\section{REFERENCES}

Andrianoelina AO, Rakotondraoelina H, Ramamonjisoa L, Maley J, et al. (2006). Genetic diversity of Dalbergia monticola (Fabaceae) an endangered tree species in the fragmented oriental forest of Madagascar. Biod. Cons. 15: 1109-1128.

Arif M, Zaidi NW, Singh YP, Haq QMR, et al. (2009). A comparative analysis of ISSR and RAPD markers for study of genetic diversity in shisham (Dalbergia sissoo). Plant. Mol. Bio. Rep. 27: 488-495.

Arnau G, Lallemand J and Bourgoin M (2003). Fast and reliable strawberry cultivar identification using inter simple sequence repeat (ISSR) amplification. Euphytica 129: 69-79.

Bachmann K (1997). Nuclear DNA markers in plant biosystematics research. Opera Bot. 32: 137-148.

Blair MW, Panaud O and Mccouch SR (1999). Inter-simple sequence repeat (ISSR) amplification for analysis of microsatellite motif frequency and fingerprinting in rice (Oryza sativa L.). Theor. Appl. Genet. 98: 792.

Chen JM, Gituru WR, Wang YH and Wang QF (2006). The extent of clonality and genetic diversity in the rare Caldesia grandis (Alismataceae): comparative results for RAPD and ISSR markers. Quat. Bot. 84: 301-307.

Chowdhury MA, Vandenberg B and Warkentin T (2002). Cultivar identification and genetic relationship among selected breeding lines and cultivars in chickpea (Cicer arietinum L.). Euphytica 127: 317-325.

Dang NT and Nguyen TB (2007). Vietnam Red List. Sciense and Technology Publisher. 412.

Esselman EJ, Lianqiang L, Crawford DJ, Winduss JL, et al. (1999). Clonal diversity in the rare Calamagrostis porteri ssp. insperata (Poaceae): comparative results for allozymes and random amplified polymorphic DNA (RAPD) and intersimple sequence repeat (ISSR) markers. Mol. Ecol. 8: 443-451.

Goulão L and Oliveira CM (2001). Molecular characterisation of cultivars of apple (Malus domestica Borkh.) using microsatellite (SSR and ISSR) markers. Euphytica 122: 81-89.

Gupta S, Srivastava M, Mishra GP, Naik PK, et al. (2008). Analogy of ISSR and RAPD markers for comparative analysis of genetic diversity among different Jatropha curcas genotypes. Afric. J. Biotechnol. 7: 4230-4243.

Jaccard P (1908). Nouvelles recherches sur la distribution florale. Bull. Soc. Vaud. Sci. Nat. 44: 223-270.

Joshi SP, Gupta VS, Aggarwal RK, Ranjekar et al. (2000). Genetic diversity and phylogenetic relationship as revealed by inter simple sequence repeat (ISSR) polymorphism in the genus Oryza. Theor. Appl. Genet. 100: 1311-1320.

Landergott U, Holderegger R, Kozlowski G and Schneller JJ (2001). Historical bottlenecks decrease genetic diversity in natural populations of Dryopteris cristata. Heredity 87: 344-355.

Li A and Ge S (2001). Genetic variation and clonal diversity of Psammochloa villosa (Poaceae) detected by ISSR markers. Ann. Bot. 87: 585-590.

Mantel N (1967). The detection of disease clustering and a generalized regression approach. Cancer Res. 27: 209-220.

Martins M, Tenreiro R and Oliveira MM (2003). Genetic relatedness of Portuguese almond cultivars assessed by RAPD and ISSR markers. Plant Cell Rep. 22: 71-78.

Moreno S, Martín JP and Ortiz JM (1998). Inter-simple sequence repeats PCR for characterization of closely related grapevine germplasm. Euphytica 101: 117-125.

Nagaoka T and Ogihara Y (1997). Applicability of inter-simple sequence repeat polymorphisms in wheat for use as DNA markers in comparison to RFLP and RAPD markers. Theor. Appl. Genet. 94: 597-602.

Oldfield S, Lusty C and MacKinven A (1998). The World List of Threatened Trees. WCMC, IUCN., Cambridge.

Parsons BJ, Newbury HJ, Jackson MT and Ford-Lloyd BV (1997). Contrasting genetic diversity relationships are revealed in rice (Oryza sativa L.) using different marker types. Mol. Breed. 3: 115-125.

Peakall R and Smouse PE (2006). GenALEx 6: Genetic analysis in Excel. Population genetic software for teaching and research. Mol. Ecol. Notes 6: 288-295.

Penner GA (1996). RAPD Analysis of Plant Genomes. In: Methods of Genome Analysis in Plants (Jauhar PP, ed.). CRC, Boca Raton, 251-268.

Porebski S, Bailey LG and Baum BR (1997). Modification of a CTAB DNA extraction protocol for plants containing high polysaccharide and polyphenol components. Plant Mol. Biol. Rep. 15: 8-15.

Prevost A and Wilkinson MJ (1999). A new system of comparing PCR primers applied to ISSR fingerprinting of potato

Genetics and Molecular Research 10 (4): 2382-2393 (2011)

CFUNPEC-RP www.funpecrp.com.br 
cultivars. Theor. Appl. Genet. 98: 107-112.

Raina SN, Rani V, Kojima T, Ogihara Y, et al. (2001). RAPD and ISSR fingerprints as useful genetic markers for analysis of genetic diversity, varietal identification, and phylogenetic relationships in peanut (Arachis hypogaea) cultivars and wild species. Genome 44: 763-772.

Rohlf FJ (1992). NTSYS-PC: Numerical Taxonomy and Multivariate Analysis System Version 2.0. State University of New York, Stony Brook, New York.

Rout GR, Bhatacharya D, Nanda RM, Nayak S, et al. (2003). Evaluation of genetic relationships in Dalbergia species using RAPD markers. Biodivers. Conserv. 12: 197-206.

Souframanien J and Gopalakrishna T (2004). A comparative analysis of genetic diversity in blackgram genotypes using RAPD and ISSR markers. Theor. Appl. Genet. 109: 1687-1693.

Weir BS (1990). Genetic Data Analysis - Methods for Discrete Genetic Data. Sinauer Associates, Inc., Sunderland.

Williams JG, Kubelik AR, Livak KJ, Rafalski JA, et al. (1990). DNA polymorphisms amplified by arbitrary primers are useful as genetic markers. Nucleic Acids Res. 18: 6531-6535.

Yap IV and Nelson RJ (1996). Winboot: A Program For Performing Bootstrap Analysis of Binary Data to Determine the Confidence of UPGMA-Based Dendrograms. IRRI, Manila.

Zhao WG, Zhang JQ, Wangi YH, Chen TT, et al. (2006). Analysis of genetic diversity in wild populations of mulberry from Western Part of Northeast China determined by ISSR markers. Genet. Mol. Biol. 7: 196-203.

Zietkiewicz E, Rafalski A and Labuda D (1994). Genome fingerprinting by simple sequence repeat (SSR)-anchored polymerase chain reaction amplification. Genomics 20: 176-183. 